\title{
Entre desigualdades, limites e relações de gênero: a democracia no Brasil*
}

Como garantir a maior participação política (nas diferentes esferas) das minorias? De que maneira é possivel superar as dificuldades enfrentadas pelas mulheres (como limitação temporal, causada pelo acúmulo de responsabilidades do trabalho doméstico, cuidado e maternidade) para um maior envolvimento político? Que direitos ainda são negados às mulheres e às pessoas LGBTQI+ pela democracia ${ }^{1}$ brasileira? Como os feminismos têm contribuído para uma sociedade mais igualitária no que tange aos direitos e à participação política? Quais foram os avanços, os limites e as desigualdades ao longo das últimas décadas no Brasil? Essas e muitas outras questões foram respondidas por Flávia Biroli no livro Gênero e Desigualdades: os limites da democracia no Brasil, publicado no ano de 2018, no qual enfatiza, como

" Recebida em 11 de setembro de 2018, aceita em 30 de novembro de 2018. Resenha de BIRoli, Flávia. Gênero e Desigualdades: os limites da democracia no Brasil. São Paulo, Boitempo, 2018.

** Doutoranda em História Cultural na Universidade Federal de Santa Catarina (UFSC), Florianópolis, SC, Brasil. rosaleneloisa@gmail.com / http://orcid.org/0000-0001-5125-9969.

1 A definição do termo democracia é com certeza uma das coisas mais complexas na atualidade. O problema é bastante antigo, uma vez que remonta tanto a noções gregas, quanto romanas, medievais, modernas, liberais $e$ socialistas (Bobbio, 1998). Sobretudo, trata-se de um termo polissêmico que assume práticas e significados em diferentes sociedades e pensamentos teóricos (Bobbio, 1998). Atualmente, no Brasil, conforme demonstrado por Flávia Biroli ao longo do livro, em função do golpe de Estado de 2016, vivemos um momento de embate e reações conservadoras que estão ameaçando de maneira direta os pequenos avanços democráticos conquistados nas últimas décadas. Em função disso, a defesa da democracia, por mais abstrata que seja, neste momento, é o tema central de muitas discussões (acadêmicas ou de movimentos sociais). 
anunciado no título, as limitações, as desigualdades e as relações de gênero presentes na democracia brasileira, a partir de uma análise que entrelaça local/global e as diferentes teorias feministas.

Flávia Milena Biroli Tokarski é formada em Comunicação Social pela Universidade Estadual Paulista Júlio de Mesquita (UNESP), e possui mestrado e doutorado em História pela Universidade Estadual de Campinas (UNICAMP). Ao longo de seus anos de pesquisadora e professora no Instituto de Ciência Política da Universidade de Brasília (UnB), tem se dedicado às temáticas da democracia, política, estudos de gênero e teoria feminista, sobretudo, com enfoque nas áreas de mídia e política. Suas principais publicações, além do livro resenhado aqui, são: Caleidoscópio convexo: mulheres, política e mídia (2011, publicado com Luis Felipe Miguel), Autonomia e desigualdades de gênero: contribuiçóes do feminismo para a crítica democrática (2013), Família: novos conceitos (2014) e Feminismo e Política (2014, também com Luis Felipe Miguel).

Sob a ótica de que "gênero é uma questão política aguda" (Biroli, 2016:09), a pesquisadora buscou avaliar tanto as tensões entre permanência e mudanças durante as últimas décadas no Brasil quanto "compreender em que pontos estamos, isto é, quais os impasses [que] se apresentam quando temos como referência a construção de relações de gênero que sejam mais justas" (Biroli, 2016:10). Além disso, trouxe ao debate velhas tensões como: entre individual e universal; a construção da separação das esferas pública e privada e a crítica feminista a respeito; os atravessamentos constituídos nas/pelas hierarquias de gênero, classe e raça; as desigualdades de gênero (entre homens $e$ mulheres, mulheres $e$ mulheres $e$ homens $e$ homens) sob diferentes aspectos como a responsabilização (do trabalho doméstico, cuidado e maternidade) e os direitos à sexualidade e ao corpo; e a atuação política feminista dentro do Estado brasileiro nas últimas décadas; entre outras questões. Todos esses eixos centrais, presentes no livro Gênero e Desigualdades, foram permeados por um vasto debate crítico e epistemológico feminista 
e de gênero e pelo que foi denominado por Joan Scott como o paradoxo da igualdade e da diferença (Scott, 2005).

No primeiro capítulo, denominado $A$ divisão sexual do trabalho, o objetivo central da autora foi demostrar a conexão entre a divisão sexual do trabalho $e$ a sub-representação política das mulheres. Para ela, isso ocorre a partir de dois pressupostos: a divisão sexual do trabalho é a base fundamental na qual se assentam as hierarquias de gênero; raça $e$ classe fazem com que hierarquias de gênero assumam formas diferenciadas (Biroli, 2018:23). Além disso, de modo geral, Biroli apresentou um panorama acerca dos debates sobre a opressão que as mulheres sofrem em relação à divisão sexual do trabalho e demonstrou, através de índices atuais, os impactos diferenciados que recaem sobre as mulheres negras em função dos atravessamentos de raça. Por último, neste capítulo, destaca que a divisão sexual do trabalho tem caráter estrutural, é produtora de gênero e que "quem realiza o trabalho doméstico enfrenta restrições no acesso a recurso políticos fundamentais" (Biroli, 2018:44). Ademais, cabe às pesquisadoras $e$ aos pesquisadores, em suas análises sobre desigualdades e democracia, indagarem-se sobre as limitações existentes para uma maior participação das mulheres na política.

A divisão sexual do trabalho entrelaça-se diretamente aos aspectos do segundo capítulo, Cuidado e Responsabilidades. Nesse capítulo, a autora também explicita que existe um paralelo direto entre as posições de desvantagens no âmbito do cuidado $e$ a exclusão ou baixa participação na política. Somados a isso, pesam padrões de responsabilização $e$ formas de concentração de poder, o que faz a autora concluir que "o ambiente institucional em que o cuidado é provido é resultado de decisões políticas" (Biroli, 2018:54). De modo geral, a pesquisadora apresentou sobre os debates teóricos que rondam a temática do cuidado e suas responsabilizações, a divisão sexual do trabalho $e$ as desigualdades, atravessadas também por classe e raça, que recaem sobre as mulheres. Para ela, a "sub-representação nas arenas institucionais não podem ser explicadas sem uma crítica da vida cotidiana e dos padrões sociopolíticos que nela se escoram" 
(Biroli, 2018:52). O que constatei nesse capítulo foi uma discussão muito pautada no Norte Global e nos debates centrados no Estado de Bem-Estar Social; no entanto, as condições criadas precisam ser melhor discorridas, especialmente quando o objeto de análise é o Brasil.

No capítulo seguinte, Familia e Maternidade, a autora demostrou as ambiguidades, debates e disputas que giram em torno das temáticas da família e da maternidade. Biroli aponta que falar sobre a família consiste em falar tanto a respeito de controles (sobre os corpos e a normalização dos afetos) quanto sobre os privilégios $e$ as desigualdades (que muitas vezes determinam a concepção de família e não reconhecem os acessos e desigualdades de recursos e direitos) (Biroli, 2018:92). Isto é, trata-se de lidar com ambivalências (Biroli, 2018:91). A partir dessa discussão de controle, privilégio e desigualdades, a autora sinalizou que é na temática da maternidade que são percebidas as maiores desigualdades de gênero, e entre as famílias, em função da raça e da classe. Ainda nesse capítulo, Biroli apresentou as transformações sociais vividas no Brasil a partir dos anos de 1970 no que diz respeito ao casamento, divórcio, aos debates que ainda permanecem acerca do casamento homoafetivo e às disputas, em função da emergência de grupos conservadores, em torno (e com palavras de ordem a partir de uma noção moralista) da família.

Nos três primeiros capítulos de Gênero e Desigualdades: os limites da democracia no Brasil, os eixos giraram em torno do caráter diferencial no tratamento dado às mulheres em relação a domesticidade, divisão do trabalho, responsabilização de certos trabalhos $e$ funções, $e$ às desvantagens que todas essas atribuições trouxeram à vida delas, seja no cotidiano seja na restrição à participação política. Além disso, a autora demarcou que pautas que atravessam diretamente os mecanismos criadores de desvantagens citados acima possuem relação direta com investimentos públicos e legislações emancipatórias que garantam/garantiram direitos às minorias, como creches, acesso à educação, casamento homoafetivo e adoção. Nesse sentido, a partir do debate realizado pela autora, como garantir uma 
igualdade de direitos e de participação política se as diferenças sociais e de gênero coloram tantos limites? Esse foi um dos grandes desafios rompidos pelos movimentos feministas $e$ LGBTQI+, com a persistência de atuação e com os avanços nas últimas décadas.

Já no capítulo quatro, Aborto, Sexualidade e Autonomia, Biroli apresentou as várias discussões que permeiam tais temas, como as dificuldades quanto ao exercício seguro da sexualidade, os debates em relação ao aborto no contexto brasileiro, $e$ as políticas racistas e eugênicas de controle populacional, implantadas no Brasil e no mundo durante o século XX. De um modo geral, a autora relaciona as discussões acerca do aborto $e$ da sexualidade àquelas de autonomia e de direitos reprodutivos, assinalando a importância de ouvir as vozes das mulheres para sair de concepções abstratas; para a autora, só a partir da escuta das mulheres é possível perceber a convergência entre gênero, raça, classe, sexualidade e lugar de origem global (Biroli, 2018). Além disso, como também apresentado nos capítulos anteriores, Biroli deu destaque às reações conservadoras, pautadas, sobretudo, na "defesa da família" e no combate à "ideologia de gênero", emergentes nos últimos anos. Nesse capítulo, senti falta dos debates sobre o aborto durante a última Constituinte e a Constituição brasileira.

Essa sensação de ausência logo foi respondida com o último capítulo, intitulado Feminismo e Atuação Política. Nele, Flávia Biroli apresentou um panorama histórico acerca da participação política de mulheres, das lutas por direitos e do feminismo brasileiro. Iniciou com as dificuldades e obstáculos enfrentados na atualidade, passando pela conquista do direito ao voto em meados do século XX, pela participação das mulheres nos movimentos de resistência à ditadura, pela emergência do movimento feminista nos anos de 1970 e 1980 e pela intensificação da luta por direitos dentro do Estado, a partir do Conselho Nacional de Direitos da Mulher (CNDM). Neste último tema, a autora deu bastante destaque às emendas apresentadas na Assembleia Constituinte de 1987, às conquistas e derrotas com 
a nova Constituição de 1988, e ao novo capítulo - com avanços e retrocessos - com a eleição do PT ao governo federal a partir de 2003. Além disso, assinalou que o "viés de representação não [está] propriamente calcado na ausência de participação política, mas na desigualdade no acesso a recursos para definir o que tem relevância no debate político [...]" (Biroli, 2018:201) e que a "atuação feminista no âmbito estatal precisa ser pensada no contexto de restrições e limitações", vividas desde a década de 1980 até a atualidade a partir de picos e refluxos (Biroli, 2018:201).

Ao longo do livro, a autora retomou discussões clássicas dos feminismos europeu, norte-americano e brasileiro, como as de Mary Wollstonecraft, Simone de Beauvoir, Alexandra Kollontai, Angela Davis, Betty Friedan, bell hooks, Judith Butler, Christine Delphy, Jacqueline Pitanguy, Nancy Fraser, Lélia Gonzalez, Helena Hirata, Jules Falquet, Patricia Hill Collins, Kimberlé Crenshaw, Gayle Rubin, Carole Pateman, Heleieth Saffioti, Sonia E. Alvarez, entre tantas outras autoras citadas. No entanto, em seu diálogo entre local e global, não há grandes comparações com países da América do Sul e pouca foi a utilização dos questionamentos provenientes dos feminismos de/des/póscoloniais. Ademais, apesar de estar em constante diálogo com os debates sobre a educação e a violência ao longo do livro, considero que tais temáticas deveriam ter recebido um capítulo específico, uma vez que foram/são pautas extremamente importantes dos movimentos feministas, ocupando bastante espaço e tempo nas demandas (como sinalizado pela própria autora no livro) e são os tópicos de grandes esforços por parte dos grupos conservadores na atualidade.

O livro Gênero e Desigualdades: os limites da democracia no Brasil, escrito por Flávia Biroli, é um material atual para quem busca saber mais sobre as conexões entre os feminismos contemporâneos (e a atuação institucional desses movimentos), sobre a democracia no Brasil, e sobre a democratização de direitos. Nos primeiros três capítulos a autora explicou sobre as limitações que as mulheres enfrentam, a partir de seu caráter diferencial construído pelo gênero, para poder participar 
ativamente na política; no quarto capítulo apresentou sobre o controle e a busca por direitos ligados ao corpo, a partir do aborto, sexualidade e direitos reprodutivos; já no quinto capítulo apontou sobre a crescente atuação das mulheres ao longo do século XX e início do século XXI. De modo geral, a autora sintetiza as principais demandas feministas durante as últimas décadas e as conexões com o Estado brasileiro, sempre se pautando em dados fornecidos pelos Instituto Brasileiro de Geografia e Estatística (IBGE) e Instituto de Pesquisa Econômica Aplicada (IPEA), entre outros relatórios de diferentes instituições, $e$ debates atuais presentes na sociedade brasileira, como as reações dos movimentos conservadores.

Os argumentos estão bem conectados e escritos de maneira coesa, oferecendo uma análise profunda na qual é possivel perceber como os eixos centrais do livro, conforme informado pela autora, afetam profundamente a vida de todas as pessoas, embora desigualmente (Biroli, 2018). Além de apresentar a história do feminismo brasileiro $e$ as desigualdades e limitações impostas às minorias no Brasil, também foram exibidos ao longo do livro as transformações nas últimas décadas e as instabilidades, os desafios e os receios atuais (diante do golpe de 2016 e as várias reformas que estão extraindo aos poucos direitos conquistados até então) para a construção de uma sociedade democrática mais justa $e$ igualitária. Por isso, o livro Gênero e Desigualdades é uma leitura obrigatória para quem busca entender o debate atual sobre a democracia no Brasil.

\section{Referências bibliográficas}

Biroli, Flávia. Gênero e Desigualdades: os limites da democracia no Brasil. São Paulo, Boitempo, 2018.

BoBBIO, Norberto. Democracia. In: BoBBIO, Norberto; MATTEUCCI, Nicola; PASQUINO, Gianfranco (org.). Dicionário de política. 11. ed Brasília, Editora Universidade de Brasília, 1998, pp.319-329. Tradução: Carmen C. Varriale et alii. 
ScotT, Joan W. O enigma da igualdade. Revista Estudos Feministas, vol.

13, n. 1, Florianópolis, IEG/UFSC, jan. 2005, pp.11-30. 